\title{
A BRASILIANÍSTICA COMO UM CAMPO DE ESTUDOS ALEMẤO SOBRE O BRASIL E SUA LÍNGUA
}

\section{THE "BRASILIANÍSTICA” AS A GERMAN STUDY FIELD ABOUT BRAZIL AND ITS LANGUAGE}

\author{
André Stefferson Martins Stahlhauer \\ Institut für Romanistik - Friedrich Schiller Universtität Jena \\ Romanisches Seminar - Leibniz Universität Hannover
}

Resumo: Este trabalho consiste em uma observação do espaço de enunciação, conforme Eduardo Guimarães (2002), do português do Brasil na Alemanha. Sob a ótica dos estudos enunciativos sobre as Políticas de línguas, observamos como se constitui um espaço de enunciação para a língua, a cultura e as mídias do Brasil no modo de representar no exterior, como uma forma de distribuição política da língua que se dá pela inserção desses estudos no campo da Brasilianística, configurando simbolicamente um campo científico disciplinar sobre o Brasil no exterior.

Palavras-chave: Brasilianística; língua; Brasil; Alemanha; enunciação.

Abstract: This paper consists in a study about space of enunciation, in according to Eduardo Guimarães (2002), of the Portuguese from Brazil in Germany. From the point of view of the enunciative studies about Language Policies, we observe how were constituted an enunciation space that represents abroad, from the point of view of the foreigner about the brazilian, the language, the culture and the medias from Brazil, as a form of political distribution of the language occurs by the insertion in the field of "Brasilianística", thus symbolically configuring a disciplinary scientific field about Brazil abroad.

Key words: Brasilianística; language; Brazil; Germany; enunciation.

\section{Um panorama do espaço enunciativo do ensino e pesquisa para a língua do Brasil na Alemanha: um espaço político de distribuiçáo de línguas aos falantes}

Apresentamos neste texto uma parte da reflexão que viemos fazendo em uma pesquisa mais ampla sobre os diferentes modos de distribuiçáo do Português ${ }^{1}$ em espaços de enunciação a partir da produção de um saber

\footnotetext{
${ }^{1}$ Vou tomar aqui as designaçôes de Português e Português brasileiro para observar o que se considera como a língua falada no Brasil. Vou tomá-las, entấo, como objeto do conhecimento linguístico do e no Brasil em sua diferença com outros objetos, tais como os designados como
} 
sobre a língua e seus entornos na Alemanha (STAHLHAUER, 2016). Trazemos aqui, então, uma análise enunciativa em política de línguas, com base em Eduardo Guimarães (2002; 2003), que visa a observar a configuração da Brasilianistik como um campo científico de estudos sobre a cultura, a mídia, a história e a língua do Brasil, na Alemanha². Ao observarmos que o funcionamento das línguas se dá historicamente pelo modo como elas são distribuídas em espaços de enunciação (GUIMARÃES, 2003), na relação de umas com as outras, é preciso salientar que, apesar de parecer uma obviedade, o português na Alemanha é distribuído como uma língua estrangeira, pois a produção do saber sobre a língua não se dá institucionalmente no interior dos estudos de uma língua oficial ou materna. Nesse sentido, é preciso considerar que os estudos sobre a língua do Brasil, que configuram o campo do saber da Brasilianistik (doravante, Brasilianística), constituem-se já afetados por uma política sobre a língua e sobre o conhecimento sobre ela, que imbricam uma história marcada por práticas alemãs de estudos sobre o Brasil, sobre o português e o português brasileiro, e uma divisão posta pela consideração de que o português, língua oficial e nacional do Brasil (GUIMARÁES, 2005; ORLANDI, 2005), não é o mesmo de Portugal, da Europa, nem tampouco o da África.

Propomos essa discussão, levando em conta que, enunciativamente, a partir da distribuição política da língua aos falantes, se dá uma produção do saber acadêmico/científico sobre o Brasil e seus aspectos socioculturais na Alemanha, processo que delimita e define esse campo de estudos como uma "subdisciplina"” da Lusitanistik, a Lusitanística, e da Romanistik, a Romanística, em países cuja língua oficial, "de expressão", é a alemã, sendo eles: Alemanha, Áustria e Suíça. Consideraremos, portanto, a constituição desse campo do saber no modo como, em enunciados de textos de um institucional, se dá a inserção do campo de estudos em universidades, na página do site da Associação alemã dos Lusitanistas, a Lusitanistenverband e.V., no institucional que narra a criação do Instituto Luso-brasileiro da Universidade de Colônia e em um ensaio intitulado Brasilianistik in Deutschland, Bra-

Português europeu, de Portugal, Português africano, ou da África, etc.

${ }^{2}$ Vale dizer que essa pesquisa é o desenvolvimento de um projeto que formulei em 2016, quando atuei como professor na UFSCar e contou com o diálogo com Soeli M. Schreiber da Silva e Nelson Viana. Em 2018, parte dessas análises foram realizadas, durante um estágio de Pós-Doutorado, que desenvolvi com a interlocuçăo de Lidia Becker, Professora do Seminários Românicos, (Romanisches Seminars) da Universidade Leibniz de Hannover, na Alemanha.

${ }^{3}$ In: Deutscherlusitanistenverband e.V. Disponível em: http://lusitanistenverband.de/pt/. Acesso em: 11 jul. 2018. 
silinística na Alemanha, de autoria de Claudius Amrbruster. Nesse sentido, observamos que se configura enunciativamente um modo de distribuir, no dizer, os objetos científicos determinados pela língua em que se escreve os textos, como modo de definir e delimitar "aquele que fala e para quem se fala” (GUIMARÁES, 2002, p. 23), instanciando no presente do acontecimento, falantes e línguas, autores e leitores, e seus lugares sociais de fala e leitura.

O campo da Brasilianística desenvolveu-se na Alemanha no século $\mathrm{XX}$, em condiçóes de produção diversas, que determinaram a formulação e a circulação dos sentidos (ORLANDI, 2012), de um discurso sobre o Brasil, sua língua, sua cultura, literatura, povo e nação. Sabe-se, ademais, que os estudos sobre o Brasil feitos por brasilianistas - e náo no interior do campo da Brasilianística, como na Alemanha, também é uma tradição nos Estados Unidos e na Inglaterra, conforme Marcio Ferrari (2016). Além disso, desde a fundação da Associaçáo dos Brasilianistas da Europa, sediada atualmente em Copenhagen, na Dinamarca, e que é composta por pesquisadores de diversas áreas e nacionalidades, vem-se produzindo interessantes materiais que fazem, do nosso ponto de vista, formular, circular e divulgar um discurso científico sobre o Brasil na Europa e com ainda pouca interlocução com instituiçôes e pesquisadores brasileiros.

Se se pode fazer um breve panorama mais geral de instituiçóes que se dedicam aos estudos, ao ensino e à pesquisa sobre o Brasil, cabe mostrar que existem inúmeros centros que instituem diferentes modos de distribuir e representar a língua do Brasil ${ }^{4}$, que é designada ora como Português ora como Brasilianisches Portugiesich, Português Brasileiro, em espaços acadêmicos, em que, pode-se afirmar, formulam-se e circulam os discursos científicos sobre a língua, tal como o Instituto luso-brasileiro que foi criado em 1932, na Universidade de Colônia, e é um dos primeiros institutos de ensino e pesquisa de português na Alemanha. Além disso, o Instituto de Romanística da Universidade de Jena sedia o posto aplicador do Certificado de Proficiência em Língua Portuguesa para Estrangeiros, o CELPE-Bras, o único exame de certificação de português oferecido e reconhecido como oficial pelo Ministério da Educação brasileiro. Vale salientar que se oferece, nos Centros de Línguas de universidades, os Sprachenzentren, o ensino em

\footnotetext{
${ }^{4}$ Como já dito anteriormente, vou considerar para esta ocasião como a língua do Brasil que ora é designada como Português ora como Português brasileiro pode significar nos textos relativamente à formação do campo científico da Brasilianística. É preciso antecipar, no entanto, que este campo de estudos, segundo o que propõe ARMBRUSTER (2010), também abrange a literatura, a cultura e a mídia, além da língua.
} 
duas modalidades, separadamente: Brasilianisches Portugiesisch, o Português brasileiro, e o Europäisches Portugiesisch, Português europeu, como línguas estrangeiras, juntamente com o ensino de outras línguas como inglês, turco, espanhol, alemão, entre outras. Há também os espaços não-acadêmicos: institutos de línguas, associaçóes brasileiras ${ }^{5}$ e luso-brasileiras, cuja prática por sobre a língua dá-se já instrumentalizada para o ensino, nas aulas, nos planos de ensino e nas representaçôes em materiais de ensino ${ }^{6}$ de Português (brasileiro) como Língua Estrangeira.

É nesse sentido que consideramos que há nessa distribuição uma prática política de sujeitos, falantes, já afetados por um saber sobre a língua que instrumentaliza o conhecimento linguístico nas diferentes práticas enunciativas sobre elas. Sendo assim, cabe uma análise do espaço enunciativo do português brasileiro que mostre o modo como se dá essa distribuição no e para o estrangeiro em relação ao brasileiro, na Alemanha. É preciso ressaltar aqui que consideramos "o estrangeiro" como um modo de alocutar o outro, como uma representaçáo de um falante de outra naçáo, no dizer, na linguagem, ou seja, que, assim como o falante, esse modo de representaçáo na língua é uma figura da enunciação, constituída no modo como a língua está dividida pelo falante 7 . Desse modo, tomamos a distribuição do português do Brasil no e para o estrangeiro, pois, na Alemanha, a constituição de um saber sobre o Português do Brasil dá-se por significar na ordem do outro (não-brasileiros), os alemães. $\mathrm{O}$ português do Brasil, nesse caso, não é uma língua oficial, tampouco nacional ${ }^{8}$, na Alemanha, e é distribuído como uma língua estrangeira e, este saber sobre a língua, o que se constitui no âmbito de estudos da Brasilianística, não se dá como uma prática científica brasileira, já que a sua produção e circulação dá-se eminentemente no espaço acadêmico alemão. Institui-se, portanto, um campo de estudos sobre a língua do Brasil, em que se representa a língua do e no Brasil, por alemães.

Consideramos esses aspectos da linguagem sob a ordem do simbólico.

\footnotetext{
${ }^{5}$ Conforme indica o site do Ministério das Relaçôes Exteriores do Brasil, disponível em: http://www.brasileirosnomundo.itamaraty.gov.br/a-comunidade/associacoes-brasileirasexterior/\#ALEMANHA. Acesso em: 30 mai. 2016.

${ }^{6}$ Há diferentes materiais de ensino produzidos por editoras alemãs, apenas para citar alguns exemplos: o “Oi, Brasil!", da editora Hueber, e o Beleza!, da editora Klett, para a modalidade brasileira e o Olá, Portugal!, para a modalidade europeia, também da editora Klett.

${ }^{7}$ Conforme uma definição em Guimarães (2006, p. 14), Língua estrangeira é a língua cujos falantes são o povo de uma Nação e Estado diferente daquele dos falantes considerados como referência.

${ }^{8}$ A menos que se considere como falantes, os cidadãos brasileiros que vivem na Alemanha.
} 
Nesse sentido, pretendemos mostrar os movimentos de sentidos que se dáo nas enunciaçôes sobre essa língua a partir de sua distribuição nesse campo de estudos, tendo em vista que essa prática também constitui a "produção de um saber metalinguístico" (AUROUX, 2001, p. 16), pois inscreve historicamente a produção do conhecimento sobre a língua, além de constituir um imaginário sobre a língua do Brasil e seus falantes na ordem do outro, do estrangeiro.

É importante salientar, também, que não há no Brasil estudos em Brasilianística. Esta é uma designação alemã para os estudos sobre determinadas áreas do conhecimento como a cultura, língua, arte e mídia do Brasil. Podem relacionar-se institucionalmente a esse campo a Lusitanística e a Romanística, bem como os estudos portugueses e os estudos latino-americanos. Estas práticas institucionais/acadêmicas desenvolveram no século XX, destacável produção científica sobre o Brasil no exterior. Segundo os pesquisadores dessa área na Alemanha ${ }^{9}$, a Brasilianística não se confunde com os Brasilienstudien, que se pode traduzir por estudos brasileiros. Esses estudos diferem-se na medida em que o primeiro se define no interior de outras subdivisóes, tendo no português e no galego o ponto comum para a configuração do campo do saber. Já o segundo caracteriza-se por estudos mais gerais sobre o Brasil, como campo autônomo do conhecimento, que não é definido em função de outro subgrupo. Além disso, é preciso salientar, que ambos os estudos são realizados, salvo exceçôes ${ }^{10}$, por pesquisadores alemáes e ainda que tenham sido feitos por meio de algumas parcerias com instituiçôes brasileiras, sempre contam com a transferência de saber produzido fora do Brasil, por uma prática científica outra, com teorias e objetos, técnicas, metodologias e olhares outros que não o brasileiro.

Vale dizer, ainda que este não seja o foco deste texto, que as práticas enunciativas que configuram o saber e o conhecimento sobre o Brasil também determinam a produção de instrumentos linguísticos (AUROUX, 2001). Além das gramáticas e dicionários, pode-se considerar que os materiais de ensino de Português brasileiro instauram modos de instrumentalizar as línguas. Por meio da produção de um discurso sobre a língua do Brasil formulam-se as enunciaçóes desses instrumentos linguísticos. Tais práticas configuram-se institucionalmente e produzem diferentes lugares sociais de enunciação seja na ordem do oral, do escrito, do formal e do informal. Des-

\footnotetext{
${ }^{9}$ Dietrich Briesemeister (sem data, disponível em: http://www.brasilianistik.de/STUDIEN/ studien.htm. Acesso em: 12 jul. 2018) e Claudius Armbruster (2010).

${ }^{10}$ É necessário mencionar o importante trabalho da Professora Ligia Chiappini, brasileira que foi professora da cadeira de Brasilinística na Universidade Livre de Berlim.
} 
sa maneira, produzem-se enunciativamente os manuais (gramáticas e dicionários), planos de ensino, ementas, exames de proficiência, panfletos de propagandas de curso, entre outros materiais, configurando movimentaçóes enunciativas que vão instituindo, do dizer à textualidade, modos de escrita nos textos de institucionais, e de materiais sobre a língua.

\section{Alinhamentos teóricos: os espaços de enunciação e a produçáo de um saber metalinguístico}

Os trabalhos científicos no campo da História das Ideias Linguísticas (HIL) têm construído, tal como em Auroux (1988), a partir da convergência entre temas e perspectivas teóricas, uma gama de referências para a observação da construção de um "saber metalinguístico" e, com isso, têm formulado e fornecido conhecimento teórico para pensar a produção de um saber sobre a língua. A partir dos trabalhos em Semântica do Acontecimento, pela noção de espaço de enunciação em Eduardo Guimarães (2002), considerarei a distribuição do português do Brasil no quadro do que delimito como o espaço institucional do ensino e da pesquisa na Alemanha, levando em conta a especificidade do conceito para descrever e interpretar a "distribuição da língua aos seus falantes" (GUIMARÁES, 2002).

Quando se observa uma língua em um espaço de enunciação, tem-se como foco o funcionamento da divisão política das línguas: i) seja no movimento interior de unidade e diversidade, como quando consideramos o "uso de uma variedade" do português, português brasileiro e português europeu, e ainda como essa redivisão identifica o falante por falar determinado sotaque do português do Brasil, ou seja, o gaúcho, o caipira, e outros. Ou podemos considerar, ainda, ii) esse espaço pelo modo como significa e distribuem-se línguas diferentes, como quando se pode observar as relaçóes entre o português e o francês na Suíça, conforme analisado em Stahlhauer e Schreiber da Silva (2016) e Stahlhauer (2018).

Em Guimarães (2002, p. 13), encontramos explicitada a noção de espaço de enunciação:

são espaços de funcionamento de línguas, que se dividem, redividem, se misturam, desfazem, transformam por uma disputa incessante. São espaços "habitados" por falantes, ou seja, por sujeitos divididos por seus direitos ao dizer e aos modos de dizer. São espaços constituídos pela equivocidade própria do acontecimento: da deontologia que organiza e distribui papéis, e do 
conflito, indissociado desta deontologia, que redivide o sensível, os papéis sociais. O espaço de enunciação é um espaço político (...).

O espaço de enunciação, tal como é definido por Guimarães é um espaço político em que se articulam a política e o político. A primeira é a instância da normatividade e o segundo é a contradição dessa normatividade. O político define, entáo, a tensão que determina o que se diz e o modo como diz um Locutor. Ou seja, a língua na e pela qual se diz, funciona a partir dessas divisóes que, enunciativamente, especificam suas formas, textualizam enunciados que, por suas vezes, configuram regularidades linguísticas.

Considerar a divisão da língua no espaço de enunciação é importante para pensar, por exemplo, como a língua é distribuída no ensino de línguas pelo modo como a enunciação da designação de uma língua é formulada na textualidade dos instrumentos linguísticos: nos institucionais dos cursos, nos planos de aula, nos materiais instrucionais (nos materiais de ensino, no modo de recortar os materiais autênticos, com a finalidade de instruir). Pode-se pensar, ainda, por meio dessa representação da língua nos materiais, o modo como as materialidades linguísticas são representadas e textualizam-se entre o formal, informal, oral e escrito, em que se delineiam um "contexto" de uso, o interacional, dessas formas.

A enunciação desses processos está agenciada pelo modo como a língua é distribuída nesse material e esse processo simboliza, escreve, os diferentes tipos de textos que fazem circular o discurso sobre a língua para ser repetido, reformulado, negligenciado ou silenciado. Retomando as questóes sobre o acontecimento e espaço político, citamos Guimarães (2002, p. 18), para quem, considerar o político na enunciação é levar em conta:

a relação entre a língua e o falante, pois só há línguas porque há falantes e só há falantes porque há línguas. E esta relação não pode ser tomada como uma relação empírica do tipo: em uma certa situação as pessoas falam na língua $x$, em outra, na língua y. Por exemplo, no Brasil se fala Português, na França, Francês, etc. Ou ainda, no Paraguai se fala espanhol e o Guarani. Esta relação entre falantes e línguas interessa enquanto um espaço regulado e de disputas pela palavra e pelas línguas, enquanto espaço político, portanto. A língua é dividida no sentido de que ela é necessariamente atravessada pelo político: ela é normativamente dividida e é também a condição para se afirmar o pertencimento dos não incluídos, a igualdade dos desigualmente divididos. 
Os espaços de enunciação são caracterizados por seu caráter político-simbólico e têm a ver com a relação língua/falante, com o modo como a língua é dividida e distribuída (GUIMARÁES, 2002) nesse espaço. O espaço de enunciação não é um espaço geográfico que evocaria o "uso" da língua/dialeto/sotaque/variantes. $\mathrm{O}$ espaço enunciativo constitui-se necessariamente de um movimento de línguas no acontecimento. A noçáo de espaço de enunciação tem a ver com o enunciável e o político, com o agenciamento enunciativo: aquilo que se diz, o modo como se diz e quem diz em um espaço afetado por uma política por sobre a língua. Dessa maneira, quando observamos a formaçáo de um campo de estudos sobre o Brasil e sua língua no interior dos estudos de Brasilianística, estamos considerando um espaço de enunciaçáo institucional para o ensino e a pesquisa de português do Brasil na Alemanha.

Referimo-nos, assim, aos espaços de distribuição das línguas em que se formulam e distribuem, no campo cientifico, o saber e o conhecimento sobre a língua, seus falantes e seus entornos: sua literatura, a cultura, a mídia, etc. Nesse sentido, a enunciação nesse espaço significa por um modo de dizer esses objetos do conhecimento de um lugar agenciado de sentidos, por um modo de fazer ciência, que é já, historicamente, uma prática enunciativa, e portanto política, de dividir, no dizer, nas enunciaçóes, os objetos científicos, que, nesse caso, são os estudos que se formulam nos textos de institucionais e nos instrumentos linguísticos, nos materiais de ensino de e sobre o português do Brasil, que são escritos de uma posição específica, já afetada por uma prática alemã de formular e fazer circular o saber sobre a língua para alemães.

Nessa perspectiva, no caso da configuração de um espaço para dizer institucionalmente e formular o saber acadêmico/cientifico e artístico sobre o Brasil e sua língua na Alemanha, identificamos, de início, ao menos três formas de distribuição:

I - A criação dos institutos e associaçôes de pesquisa e seus institucionais ${ }^{11}$;
II - A inserção dos cursos de português brasileiro nos centros de línguas e
institutos de idiomas, que se dá eminentemente através do campo do ensino
de Português Língua Estrangeira, e o credenciamento da Alemanha na orga-
nização e realização o exame Celpe-Bras;
III - A produção de materiais específicos para instrumentalização do Portu-
guês brasileiro.

${ }^{11}$ Consideramos como um institucional o texto que apresenta, define, em suas formas de designar e representar, "expor objetos ao real” (GUIMARÁES, 2002), uma instituição. 
Essas três formas distintas configuram simbolicamente discursos sobre a língua que instituem diferentes formas de distribuir o português do Brasil no espaço da pesquisa em textos de diferentes tipos, em institucionais, ensaios, artigos, textos de divulgação, etc. Além disso, elas instituem uma injunçâo à leitura que projeta uma futuridade para esses textos. Eles são escritos somente em alemáo ou também podem ser traduzidos para o português para serem lidos por pesquisadores, professores e estudantes, interessados no campo acadêmico, etc. Dito de outro modo, esses textos são escritos para fazer circular os sentidos ali formulados.

Dessa forma, há uma divisão que caracteriza a distribuição política dos sentidos das diferenças na(s) língua(s) - principalmente, porque essa distribuição dá-se por divisóes em português, português brasileiro e português europeu. Essas diferenças aparecem nos textos na medida em que elas constituem modos de dizer sobre o português do e no Brasil e, sobretudo, sobre a divisão português e brasileiro, que identifica necessariamente os seus falantes ${ }^{12}$.

As análises sobre os períodos de distribuição do português, em Guimarães (2005), mostraram como a língua tornou-se oficial, nacional e materna no Brasil. Estas análises mostraram também que esse processo é o efeito de uma história e de uma política de distribuição de lugares e modos de enunciação de uma língua, que se institui por uma política sobre a língua. E inspirados por essas análises, tomamos esses processos na Alemanha. Olhar, assim, para a distribuição das línguas é, a nosso ver, verificar como aquilo que se diz sobre elas, é parte de uma história, um gesto interpretação, e também de leitura e escrita.

\section{A gestáo da leitura e as línguas na constituiçáo dos leitores}

Os nossos dados se comporáo de três recortes, sendo dois de textos em português e um em alemão. Salienta-se que a língua em que se enuncia e em que o texto é escrito inscreve uma alocução (GUIMARÃES, 2011) e projeta diretamente uma possibilidade de leitura e, por isso, a constituição

\footnotetext{
${ }^{12}$ Faz-se necessário considerar, ainda, as diferentes designações que redividem os modos de acesso e distribuição da língua: Português Língua de Herança, Português Segunda Língua, Português Língua Adicional, etc. A questão das variantes, e de outras divisōes, como o português e o brasileiro ou o português do Brasil sáo designaçóes que formulam posiçóes distintas em relaçáa à identificação do locutor-professor do português do Brasil ou do locutor-professor de português europeu, predicados no modo de significar a língua.
} 
de um leitor para este texto. Se em alemão e traduzido para o português ou se somente em alemão, o autor do texto projeta um leitor (GUIMARÁES, 2011) para si e esse movimento, inclusive, determina o modo como e em que instâncias esses textos e esses discursos sobre a língua podem circular. Ou seja, é essa mesma movimentação enunciativa na escrita do texto em uma língua ou sua tradução ou em outra língua, que permite interpretar que falante escreve e para quem ele escreve e faz circular um saber sobre o Brasil, sua língua, cultura, literatura, etc. Esse modo de gestão da escrita do texto é, então, um modo de distribuir a língua e o saber sobre ela para o outro.

\section{Brasilianística e a Lusitanística: a divisão científica em subdisciplinas}

Neste primeiro exemplo, no texto do site da Associaçáo Alemá de Lusitanístas, a Deutscher Lusitanistenverband e. V., observa-se o modo como a Brasilianística é definida como uma subdisciplina da Lusitanística, assim como a Portugalística, a Afrolusitanística.

Lusitanística em universidades de língua alemã - possibilidades de estudo

Objetivo do levantamento

A Lusitanistica abrange a investigação e o ensino sobre os países de expressão portuguesa. As subdisciplinas da Lusitanística são designadas segundo países, continentes ou variantes linguísticas (Portugalística, Brasilianística, Afrolusitanística e Creolística).

Tradicionalmente a Lusitanística é um ramo da Romanística; no entanto a Lusitanística é amiúde parte integrante de programas de estudo como Ciências Regionais, Ciências da Cultura e Estudos de Traduçáo.

Nestas páginas poderá encontrar informaçôes sobre as possibilidades de estudo de Lusitanística em universidades alemãs, austríacas e suíças, incluindo variantes disciplinares e tipos de diploma em oferta.

O levantamento foi levado a cabo por Conrad Schwarzrock, Trier.

O ponto fundamental que chama a atenção nesse recorte é o modo como se estabelece uma certa relação hierárquica entre disciplinas e subdisciplinas por uma determinação identitária de inclusão a determinado grupo de falantes. Ou seja, a divisão entre uma disciplina e uma parte dela, uma subdisciplina, dá-se justamente pela composição de um todo maior de estudos. A questáo que deriva dessa divisão é justamente o modo como o entorno da língua, o modo de expressão, significa e distribui uma língua, o 
português, e suas "variantes linguísticas", nesse caso em relação a esse todo e não em relaçáo à parte, processo em que se inscreve um imaginário de monolinguismo e homogeneidade: "A Lusitanística abrange a investigação e o ensino sobre os paises de expressão portuguesa". Nesse sentido, pode-se parafrasear, a Brasilianística é definida em relação à Lusitanística por um ponto comum. Ou seja, a designação do nome da disciplina dá-se na relação posta entre língua e país e oficialidade e, mais indiretamente, identifica esse grupamento linguístico como povo em relação ao país. É preciso trazer à tona, também, o modo como essas disciplinas e subdisciplinas estabelecem ainda outra relação de partição. Em (...) Tradicionalmente a Lusitanística é um ramo da Romanística as disciplinas compóem o "ramo", o braço, do que essa prática científica nomeia como Romanística. Dito de outro modo, pode-se interpretar que tanto as subdisciplinas como as disciplinas compóem o estudo da Romanística, ou estudo das línguas românicas.

A questão fundamental que emerge desse texto quando se interpreta em relação ao modo como se deu a constituição discursiva dos efeitos científicos nos estudos da linguagem no Brasil (FERREIRA, 2008; RODRIGUES, 2002), sobretudo na configuração científica e institucional dos campos das Letras, Linguística e Literatura, é a de que ele caracteriza-se justamente por uma aderência e a um simulacro da prática científica a uma cultura, que forja em ciência, a rememoração de um Ethnos (SÉRIOT, 1997), que se exacerba à língua do outro. Nesse sentido, a cultura que configura uma identidade alemã na prática científica dá-se justamente pela distribuição da língua em um grupo, uma família, no caso, o das línguas românicas.

\section{Português brasileiro e europeu}

Por meio dessa análise do espaço de enunciação, podemos observar que a criação de instituiçóes de pesquisa e ensino configura um modo de distribuir o português e redividir o seu funcionamento em outro institucional. Observemos como a partir do acontecimento da enunciaçáo em que se narra a criação do Instituto luso-brasileiro em 1932 na Universidade de Colônia ${ }^{13}$, a língua é significada:

13 Disponível em: http://pbi.phil-fak.uni-koeln.de/3209.html?\&L=5. Acesso em: 27 mai. 2016. 


\section{Sobre o Instituto Luso-Brasileiro}

O Instituto Luso-Brasileiro (PBI) foi fundado, em 1932, pelo romanista Prof. Dr. Leo Spitzer e é dirigido, desde 1998, pelo Prof. Dr. Claudius Armbruster. Como um dos principais centros de estudo e pesquisa da Lusitanística/ Brasilianística (designaçáo alemã para os Estudos Portugueses e Brasileiros) em universidades alemás, o PBI conta, atualmente, com cerca de 1000 estudantes inscritos, oferecendo, como único instituto universitário na Alemanha, a possibilidade de optar pelo estudo tanto do Português Europeu quanto do Português Brasileiro. Este último assume grande importância principalmente no âmbito da graduaçáo em Ciências e Estudos Regionais da América Latina, curso oferecido exclusivamente pela Universidade de Colônia (grifo nosso).

Essa institucionalização produz, de início, ao menos três modos de significar os processos sobre a língua do Brasil, significado como Português brasileiro:

I - No acontecimento da enunciação da designação de Brasilianística e lusitanística, que instaura um modo de designar pautado na divisão entre os campos dos estudos brasileiros e portugueses;

II - A que privilegia a distribuição da língua brasileira, segundo o princípio da variaçấo linguística pela diferenciaçấo entre a modalidade europeia e a brasileira;

III - A que privilegia o ensino de português brasileiro segundo um princípio geopolítico estratégico, "no âmbito da graduaçáo em Ciências e Estudos Regionais da América Latina".

O que se estabelece no modo de designar a língua nesse texto é como se instaura um modo de acesso à palavra (GUIMARÁES, 2002) ao português brasileiro, ao definir-se um campo de estudos sobre o Brasil, a Brasilianística, a partir de sua diferença com a lusitanística, e incluir aí também, nesse âmbito de pesquisa, o estudo sobre o português brasileiro. Nota-se, ainda, que há uma hierarquização nessa distribuição, pois "privilegia-se" a variante brasileira à outra "variante", a europeia. Outro ponto importante que se pode destacar desse recorte é o modo como o aspecto geopolítico funciona e determina a distribuição do português brasileiro como uma língua da "América Latina". Ou seja, há aí uma divisão que recoloca a questão da língua do Brasil e dos espaços linguísticos de dois modos, a do português no quadro das línguas da América Latina e a de lusofonia. Há aí uma divisão do sentido da designaçáo de português brasileiro, que é determinada pela divisão entre português (europeu) e brasileiro, não só por sua diferença da língua europeia, mas como uma língua da América Latina. Nesse sentido, 
mesmo que, no dizer, se toma o objeto língua como transparente, como um objeto empírico, uma variante, podemos observar que há uma determinação do conhecimento linguístico por sobre o modo de significar a língua do Brasil, já atravessada pela instrumentalização e pelo conhecimento linguístico sobre a língua do Brasil, o português brasileiro. Pode-se dizer, então, que essa diferença configura ainda, uma especificidade, dando enfoque à Brasilianística e à língua do Brasil. Se observarmos como se dá esse processo relativamente à significação da brasilianística na análise anterior, veremos ainda que há, neste caso, outro movimento de divisão entre esse campo de estudos e a Lusitanística. Nesse texto, não se evidencia a relação entre os dois campos como subdisciplinas, nem tampouco com o ramo da Romanística, o que acaba por produzir um efeito de destaque por sobre a Brasilianística como campo de estudos independente.

\section{Um ensaio sobre a Brasilianística: a metáfora do campo de orquídeas}

O próximo recorte é retirado de um ensaio, intitulado Brasilianistik in Deutschland, Brasilianística na Alemanha (tradução nossa), que integra a obra Deutsch-brasilianische: Kulturbeziehungen, Bestandsaufnahme, Herausforderungen, Perspektiven ${ }^{14}$, Alemanha-Brasil: relaçóes culturais, inventários, desafios, perspectivas (tradução nossa), cuja organização é de Bader Wolfgang. É preciso salientar que o texto apresenta uma única versão, escrita em alemão, assim como todos os outros textos da obra, que trata, entre outras coisas, das relaçóes culturais entre o Brasil e Alemanha.

\section{Ist Brasilianistik ein Orchideenfach?}

Aus brasilianischer Sicht kann man sich wohl kaum vorstellen, dass ein so großes Land mit so vielen Kulturen als wissenschaftliches Objekt in Deutschland als sogenanntes "Kleines Fach" gilt. Ist es, so ist weiter zu fragen, auch ein Orchideenfach? Dieser Begriff ist nicht unmittelbar ins Portugiesische zu übersetzen. Er meint ein kleines, aber feines Fach, in dem etwas erforscht wird, was keinen unmittelbaren Nutzwert hat und was auch in der Öffentlichkeit kaum bekannt ist. Dennoch ist Brasilianistik als Begriff eingängiger als Lusitanistik, weil sich immerhin einige unter Brasilien etwas vorstellen können, auch wenn die Bilder, die sie dabei abrufen, eher stereotyper Natur sind (ARMBRUSTER, 2010 , p. 252, grifos nossos) ${ }^{15}$.

\footnotetext{
${ }^{14}$ Disponível em: http://publications.iai.spk-berlin.de/receive/reposis-iai_mods_00000139.

Acesso em: 11 jul. 2018.

${ }^{15}$ Tradução nossa:

"5. A Brasilianística é um campo de orquídeas?
} 
Esse recorte caracteriza-se por qualificar a Brasilianística e considerá-la como um campo de estudos pequeno, exótico e sem "muitos préstimos" no sentido de que náo traz muitos resultados (econômicos?) à Alemanha. Cabe aqui retomar um trecho de um texto de Chiappini (2010) que se vale de uma asserção de Dietrich Briesemeister sobre os estudos em Brasilianística:

\begin{abstract}
Em palestra realizada no primeiro simpósio internacional promovido pela Brasilianística, "Brasil: país do passado?", que se publicou posteriormente em livro com o mesmo título, Dietrich Briesemeister (2000) faz um balanço dessa luta, do início do século XIX ao final da década de 90 do século XX, que ajuda a entender a situação presente. Começa constatando nesse percurso um permanente desequilíbrio na visăo do Brasil pelos estudiosos na Alemanha. Por um lado, seria esse País Tropical um paraíso para geólogos, botânicos, sociólogos, geógrafos, etnólogos, que sempre por ele se interessaram, sobre ele pesquisaram e escreveram. Por outro lado, e paralelamente, haveria um semidesconhecimento cultural e, mesmo, uma ignorância quanto à "participação individual do Brasil na cultura universal", vigorando "enfoques valorativos eurocêntricos e critérios preconceituosos" (BRIESIMEISTER, 2000, p. 349 apud CHIAPPINI, 2010, p. 11).
\end{abstract}

Nesse sentido, em alinhamento com o que se afirma no trecho acima, a questáo que nos interessa no recorte do texto de Armbruster (2010) é justamente o modo como o campo de estudos é designado por uma metáfora alemâ ${ }^{16}$ que significa um estudo raro, "para poucos", e que fica restrito mais ao campo acadêmico e que tem pouca "aplicabilidade". Tais afirmaçóes significam uma naturalização em que se toma um objeto histórico, a cultura, a língua, como um organismo, uma planta. A metáfora, além de naturalizar objetos históricos e do conhecimento, naturaliza também as práticas cientificas de distribuição e circulação do conhecimento, que são, necessariamente, um trabalho de sujeitos, um trabalho político-ideológico. Esse modo de

Do ponto de vista brasileiro, dificilmente se pode imaginar que um país tão grande com tantas culturas seja considerado um objeto científico na Alemanha como o chamado "pequeno campo". Entáo, pergunta-se novamente, um campo de orquídea? Este termo não é diretamente traduzível para o português. Isso significa dizer um campo pequeno, mas um campo fino, no qual algo é pesquisado, que não tem valor imediato e que também é pouco conhecido do público. No entanto, é melhor o termo Brasilíanística do que Lusitanística, porque pelo menos se pode imaginar algo sobre o Brasil, mesmo que as imagens que ela usa sejam, por natureza, estereotipadas" (ARMBRUSTER, 2010, p. 252, grifos nossos).

${ }^{16}$ Para explicações mais detalhadas, verificar: DUDEN - Die deutsche Rechtschreibun (disponível em: <https://www.duden.de/>. Acesso em: dez. 2018) e Kleines Uni-ABC. Universität Bonn, Fachschaft Psychologie (disponível em: https://web.archive.org/web/20090926213724/http:/ www.fs-psycho-bonn.de/contrexx/index.php?page=125. Acesso em: dez. 2018). 
designar a Brasilianística significa ainda que a prática de estudos sobre o Brasil, e sua língua, dá-se isoladamente no espaço científico alemão. Ou seja, os estudos em Brasilianística são uma prática que tem sido realizada com pouca interlocuçáo com os estudos acadêmicos feitos no Brasil, a partir de métodos e técnicas brasileiras. $\mathrm{O}$ trecho acaba por significar, contudo, que a prática não vai muito além dos estereótipos. Nesse sentido, esse modo de significar, considera que o estudo sobre o Brasil, sua língua, sua cultura, na Alemanha é feito para alemães, uma espécie de autofilia e de narcisismo, nos quais perpetuam-se os equívocos e estereótipos sobre o Brasil, sem observá-lo para além do seu "exotismo". A Brasilianística é, assim, nas palavras de Amrbruster, interpretamos, uma "criação" de orquídeas só para orquidófilos alemães.

\section{Consideraçóes}

Este texto apresenta uma pequena amostra de como se dá a distribuição da língua do Brasil e de seus entornos, na Alemanha, não pretendendo ser, portanto, um estudo exaustivo em que se exauriria os dados em números, estatísticas ou em um mapeamento de institutos de Brasilianística. Nesse sentido, a delimitação que se faz em relação à Alemanha não se dá relativamente à sua fronteira geográfica, mas, sobretudo, pelo modo como, simbolicamente, a prática científica por sobre a língua do Brasil constitui uma particularidade, uma identidade científica, inclusive, em detrimento da identidade científica brasileira, pois ainda há pouca interlocução com instituiçôes e pesquisadores brasileiros.

Tratamos, aqui, da análise de recortes que configuram uma pequena amostra do modo como se constitui uma imagem, uma identidade da língua do Brasil, tomada como conhecimento por outra identidade, a alemá, que forja, ainda, uma identidade científica configurada pelo modo como se distribui, inclusive no campo dos estudos linguísticos, em "subdisciplinas", em "ramos", o que acaba, também, por produzir uma outra relação de divisão com o científico ao considerar que o estudo que se faz sobre o Brasil, sua língua, sua literatura e cultura tem de ser produzido no campo da Brasilianística e não no da Lusitanística. Percorre-se, então, de recorte em recorte, as práticas enunciativas, que distribuem a língua em um movimento de autoria e leitura estabelecido na escrita de textos em português e alemão em que se representa o português brasileiro nas duas línguas, um movimento na e pela língua que distribui o objeto do saber, a língua e seus entornos, sobre o Brasil em um campo, de diferentes modos, atribuindo 
diferentes sentidos aos objetos e a esse campo científico. Sendo assim, essas textualidades e discursividades em um texto de institucional de uma associação de pesquisadores, em outro institucional de divulgação de um Instituto de ensino e pesquisa e em um ensaio em que se condensa períodos, estilos e tipos de estudo, distribui-se a língua e o conhecimento produzido sobre o Brasil por uma identidade outra, de fora, que não a brasileira.

Desse modo, esta análise da distribuição da língua do Brasil, na Alemanha, mostra que há modos de distribuição do português, de suas variantes e do português brasileiro, além de mostrar a representação da relação entre línguas por meio da divisão brasileiro e português que, para além do paradigma variacional, mostra, também, por deriva, uma política por sobre a língua que é instrumentalizada pelas instituiçóes alemãs no campo da Brasilianística, campo de estudos que não existe no Brasil. As áreas que configuram o campo de estudos sobre a língua no Brasil constituem-se, grosso modo, pelo nome do campo científico-acadêmico: Letras, Linguística (e Língua portuguesa), literaturas (em língua portuguesa), literatura brasileira e portuguesa (FERREIRA, 2008). Esse saber sobre a língua, o que se institui no campo da Brasilianística, não é produzido no Brasil, nem para brasileiros. Institui-se, portanto, um campo de estudos sobre a língua do Brasil, em que se representa a língua do Brasil apenas para alemães. Sendo assim, sob a ótica dos estudos enunciativos sobre as Políticas de Línguas, observamos como se constitui um espaço de enunciação para a língua, a cultura e as mídias do Brasil no modo de representá-la no exterior, pelo estrangeiro em relação aos brasileiros na Alemanha, como uma forma de distribuição política da língua que se dá pela inserção desses estudos no campo da Brasilianística, configurando simbolicamente, assim, um campo científico disciplinar sobre o Brasil no exterior.

\section{Referências}

AMBRUSTER, C. Brasilianistik in Deutschland. In.: Wolfgang Bader (Hrsg.) eutsch-brasilianische Kulturbeziehungen - Bestandsaufnahme, Herausforderungen, Perspektiven. Vervuert Verlag. Elisabethenstr. 3-9 D-60594 Frankfurt am Main. 2010. 
AUROUX, S. Pour une Histoire des idées linguistiques. Revue de synthese: $1 V^{\prime}$ S. NO' 3-4, p. 429-441, juil./dbc. 1988.

AUROUX, Sylvain. A revoluçáo tecnológica da gramatizaçáo. Trad. Eni Orlandi. Campinas: Unicamp, 2001.

CHIAPPINI, L. Os estudos de língua e literatura brasileiras no contexto dos estudos portugueses e latino americanos na Alemanha. Revista da ABRALIC. v. 11, n. 15, p. 9-24, 2009.

FERRARI, M. O Brasilianista por referência. Obituário. Revista FAPESP, n. 245, p. 85, 2016. Disponível em: <http://revistapesquisa.fapesp. br/2016/07/14/o-brasilianista-por-excelencia/>. Acesso em: 12 jul. 2018.

FERREIRA, A. C. F. Efeitos do científico na constituição da Linguística e da teoria literária na Unicamp. Revista Línguas e instrumentos linguísticos, Campinas, Capes-Procad-Unicamp, n. 22, 2008.

Semântica do acontecimento: um estudo enunciativo da designação. Campinas: Pontes, 2002.

Enunciação e Política de línguas. Letras - Revista do Programa de Pós-Graduaçáo em Linguística da UFSM, Santa Maria, n. 27, p. 47 53, 2003.

. A língua portuguesa no Brasil. Ciência e Cultura. vol.57. no.2 Sáo Paulo. Apr/June. 2005

Análise de Texto: Procedimentos, Análises, Ensino. Campinas: RG, 2011.

RODRIGUES, Suzy Lagazzi. A língua portuguesa no processo de institucionalizaçáo da linguística. In. GUIMARÃES, E.; ORLANDI, Eni P. (Orgs.). Institucionalizaçáo dos estudos da linguagem. A disciplinarização das idéias lingüísticas. Campinas: Pontes, 2002. p. 13-22. 
ORLANDI, E. A língua brasileira. Ciência e Cultura, São Paulo, v. 57. n. 2, p. 1-4, abr./jun. 2005.

. Discurso e texto: Formulação e circulação dos sentidos. Campinas: Pontes, 2012.

SÉRIOT, P. Ethnos et Demos: la construction discursive de l'identité collective. Langages et Société, Paris, MSH, n. 79, p. 39-52, 1997.

STAHLHAUER A. S. M.; SCHREIBER DA SILVA, S. As migraçôes e as línguas, as relaçôes entre o português e o francês na Suíça: um estudo sobre o espaço de enunciação. Língua e Instrumentos Linguísticos, Campinas, n. 36, v. 1, p. 245-265, 2016.

STAHLHAUER, A. S. M. Uma reflexão sobre o ensino de Português brasileiro na Alemanha. Os espaços de enunciação e divisão português e brasileiro. ALED Brasil, 2016, São Carlos. Trabalhos completos ALED-Brasil, São Carlos, p. 1-12, 2016. Disponível em: <http://www.revistaaledbr.ufscar. br/index.php/revistaaledbr/article/view/130/124>. Acesso em: 29/01/2019.

STAHLHAUER, A. S. M. A divisão e a distribuição do Português na Suíça: língua de imigração e de trabalhadores. In: Os sentidos da escravidáo e outros temas: análises em Semântica do Acontecimento. SCHREIBER DA SILVA, S. M.; MACHADO, C. P. (Orgs.). São Carlos: Pedro \& João Editores, 2018. p. 39-55.

ZOPPI-FONTANA, M. G.; DINIZ, L. R. A. Declinando a língua pelas injunçóes do mercado: institucionalização do português língua estrangeira (PLE). Estudos linguísticos, São Paulo, v. 37, n. 3, p. 89-119, set./dez. 2008 .

UNIVERSITAT ZU KOHN. Portuguiesisch/Brasilianisches Institut. Sobre o Instituto Luso-Brasileiro. 2009 Disponível em: <http://www.pbi. phil-fak.uni-koeln.de/3209.html?\&L=5>. Acesso em: 30 set. 2016. 
Recebido: 15/07/2018

Aceito: 01/12/2018

DOI: $10.5902 / 2179219433667$

fragmentum, n. 52, Jul./Dez. 2018. 